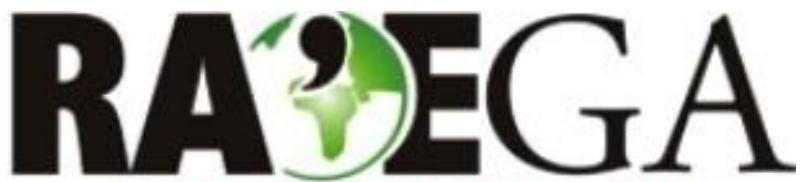

O ESPACCO GEOGRÁFICO EM ANÁLISE

\title{
AS TRANSFORMAÇÕES RECENTES NO ESPAÇO RURAL BRASILEIRO: ANÁLISES DO PAPEL DO ESTADO NAS POLÍTICAS DE DESENVOLVIMENTO RURAL DAS DÉCADAS DE 1970 A 1990
}

\section{THE RECENT TRANSFORMATION IN BRAZIL'S RURAL SPACE: STATE PAPER ANALYSIS IN RURAL DEVELOPMENT POLICIES OF DECADES OF 1970 A 1990}

\author{
Estevão Neumann ${ }^{1}$, Sergio Fajardo ${ }^{2}$,Mario Zasso Marin ${ }^{3}$
}

\section{RESUMO}

Esta revisão bibliográfica constitui-se de um esforço teórico-metodológico, com base em discussões do trabalho de dissertação de mestrado do autor. O objetivo foi realizar uma abordagem histórico-crítica do espaço rural brasileiro do pós-Segunda Guerra Mundial, verificando momentos históricos cruciais para a configuração atual do mesmo. Para isso, partiu-se de uma análise do papel do Estado nas políticas de desenvolvimento rural da década de 1970, que culminou com a modernização da agricultura (Revolução Verde), a análise a partir da constituição de 1988, mas, sobretudo, na década de 1990, quando houve a consolidação dos movimentos e organizações sociais, a descentralização do Estado e desregulamentação dos mercados. Assim, enfatizam-se as políticas públicas, à agricultura familiar e/ao agronegócio, comparando-as entre as duas décadas, apontando alguns dos impactos sociais ocasionados pelas transformações do espaço rural. Os principais resultados obtidos com as análises aqui apresentadas (das décadas de 1970 e 1990) indicam transformações que levam o agronegócio à hegemonia no espaço rural a partir do conteúdo da técnica, essa, seletiva e excludente. No entanto, o meio rural ficou fortemente marcado por lutas e organizações dos agricultores familiares, com objetivo de encontrar e manter seu espaço em meio à difusão do Modo de Produção Capitalista no campo.

PALAVRAS-CHAVE: Agricultura Familiar; Agronegócio; Movimentos Sociais; Políticas Públicas; Revolução Verde

\section{ABSTRACT}

This literature review consists of a theoretical and methodological effort, based on the author's master degree dissertation discussions. The aim was to conduct a historical-critical of the Brazilian rural areas of post-World War II approach, checking historical moments crucial to the current configuration of it. For this, it started with an analysis of the State role in rural development policies of the 1970s, which resulted in the modernization of agriculture (Green Revolution), the analysis from the 1988 constitution, but especially in the decade 1990, when there was the consolidation of social movements and organizations, decentralization of the state and deregulating markets. Therefore, it emphasizes public policy, family agriculture and / agribusiness, comparing them between the two decades, pointing out some of the social impacts caused by the transformation of rural areas. The main results of the analyzes presented here (the 1970s and 1990s) indicate changes that lead to the hegemony agribusiness in rural areas from the technical content, this, selective and excludent. However, the rural areas was strongly marked by struggles and organizations of family farmers, in order to find and keep their space through the diffusion of the Capitalist Mode of Production in the field.

KEY-WORDS: Family Agriculture; Agribusiness; Social Movements; Public Policy; Green Revolution

\footnotetext{
${ }^{1}$ Universidade Estadual do Centro-Oeste, Guarapuava/PR, e-mail: estevaoneumann@hotmail.com

${ }^{2}$ Universidade Estadual do Centro-Oeste, Guarapuava/PR, e-mail: sergiofajardo@hotmail.com

${ }^{3}$ Universidade Estadual do Centro-Oeste, Guarapuava/PR, e-mail: mariozassomarin@yahoo.com.br
} 


\section{NEUMANN,E., FAJARDO,S. E MARIN,M.Z. \\ AS TRANSFORMAÇÕES RECENTES NO ESPAÇO RURAL BRASILEIRO: ANÁLISES DO PAPEL DO ESTADO NAS POLÍTICAS DE DESENVOLVIMENTO RURAL DAS DÉCADAS DE 1970 A 1990}

\section{INTRODUÇÃO}

Nas últimas décadas, o espaço rural brasileiro passou por transformações de cunho social, político, econômico e ambiental. São visíveis as mudanças em sua infraestrutura por meio da inserção de novas tecnologias na agricultura, principalmente a partir da década de 1970 com a Revolução Verde. No entanto, a totalidade das mudanças pelas quais o espaço rural passa não se deve apenas aos pacotes tecnológicos ${ }^{4}$. É evidente que a penetração do capital estrangeiro no espaço rural tenha sido um dos principais responsáveis pelas transformações do mesmo, mas é imprescindível a análise do papel do Estado ${ }^{5}$ como mediador da entrada do capital e, consequentemente, das transformações do espaço rural.

A partir da década de 1990, entretanto, as políticas de desenvolvimento rural ganham importantes mudanças na sua orientação. Deste modo, deixam de ter cunho totalmente produtivista que beneficiava, sobretudo, os grandes estabelecimentos agropecuários passando a explorar a multifuncionalidade ${ }^{6} \mathrm{da}$

\footnotetext{
${ }^{4}$ De acordo com o paradigma da modernização produtivista, promovida pelo regime militar, o Brasil adotou um pacote tecnológico de agricultura que intensificou $o$ uso de máquinas, adubos e defensivos químicos, passando a ter um aumento significativo na produção agrícola (GRAZIANO DA SILVA, 1981).

${ }^{5}$ As intervenções públicas foram e ainda são bastante comuns na gestão das sociedades com a finalidade de criar facilidades para reorientação de investimentos do capital público e privado. Buscando amenizar as diferenças entre regiões e lugares, atua mediando interesses do capital, das classes capitalistas e em menor relevância das classes trabalhadoras (ALENCAR; MENEZES, 2009, p. 125). O Estado brasileiro se mostra, assim, forte para financiar o agronegócio e isentar os agrotóxicos de impostos, e, ao mesmo tempo, mínimo quando se trata de proteger a saúde da população e do ambiente dos impactos do atual modelo de produção dominante na agricultura brasileira (ABRASCO, 2015).

${ }^{6} \mathrm{O}$ conceito de multifuncionalidade contraria a ideia de que a agricultura tem, apenas, a função de produzir alimentos, mas atribui-se à mesma um papel determinante na manutenção das populações locais; na preservação do ambiente e das paisagens; acolhimento das populações urbanas, entre outros aspectos (SILVA; ALMEIDA, 2002). A abordagem da multifuncionalidade incorpora a noção de pluriatividade (discutiremos a pluriatividade na agricultura familiar ao final deste capítulo), considerando-se que as múltiplas funções da agricultura, para a sociedade, podem se traduzir em
}

agricultura, dando ênfase e reconhecendo o papel dos atores sociais. A reforma agrária, no entanto, ficou em segundo plano, compensada por meio de políticas públicas que tentaram amenizar a problemática.

Os avanços técnicos e científicos proporcionaram a reestruturação nos processos produtivos da agropecuária brasileira. "Com a integração da agricultura com a indústria surgiu um novo ordenamento no campo, onde a lógica produtiva do conjunto das atividades agropecuárias passa a ser orientada pelo mercado global, por meio das grandes corporações agroindustriais" (FAJARDO, 2008). Essa reestruturação traz consigo a desarticulação da forma tradicional de uso da terra, passando a ser substituída, gradualmente, pelos insumos agrícolas ${ }^{7}$. Os impactos sociais trazidos com as transformações foram intensos. A expropriação capitalista se fez e ainda se faz presente.

A década de 1970 foi marcada também pelo êxodo rural ${ }^{8}$. "A partir daquela década, milhões de agricultores migraram para as cidades, acarretando o inchaço ${ }^{9}$ delas. Dessa forma, a população urbana supera a rural em meados da década de 1970" (MELO, 2011, p. 69).

Muitos agricultores que migraram às áreas urbanas não conseguiram emprego, pois não possuíam qualificação, passando a se concentrar nas áreas menos desenvolvidas das cidades. Se antes esses agricultores proprietários

atividades exercidas por diferentes membros das famílias de agricultores, que não estão diretamente associadas à produção de alimentos para o mercado. A primeira vez em que o termo 'multifuncionalidade da agricultura e do território' apareceu foi durante a ECO-92. À época, já se discutia um rural não exclusivamente agrícola (CARNEIRO, 2005).

7 Fertilizantes, agrotóxicos, máquinas etc. (SAUER, 2008, p.14).

8 Como consequência do processo de industrialização e realização de grandes obras, principalmente a partir da década de 1950 e da modernização da agricultura no Brasil a partir da década de 1960, a população brasileira deixou de ser predominantemente rural em meados da década de 1970 (ABRASCO, 2015).

${ }^{9}$ Em 2010, 15,65\% da população brasileira vivia na área rural e $84,35 \%$ na área urbana. Dessa forma, constata-se que o intenso êxodo rural contribuiu com um expressivo aumento da população urbana (SILVA; MACIEL; MOREIRA, 2013). 


\section{NEUMANN,E., FAJARDO,S. E MARIN,M.Z. \\ AS TRANSFORMAÇÕES RECENTES NO ESPAÇO RURAL BRASILEIRO: ANÁLISES DO PAPEL DO ESTADO NAS POLÍTICAS DE DESENVOLVIMENTO RURAL DAS DÉCADAS DE 1970 A 1990}

de terras eram explorados e expropriados pelo capitalismo, agora, nas cidades, são explorados pelo capital industrial, trabalhando muitas vezes, sem especialização, no "chão" das fábricas, com excessivas horas de trabalho e recebendo baixos salários. "Diante do capitalismo global [...] submetendo-se à exploração capitalista; ampliouse, portanto, o contingente de trabalhadores serviçais, formais ou informais, externos à produção do capital, que sobrevivem à custa da massa de mais-valia social" (JORDÃO; STAMPA, 2015).

Aqueles que não migravam para as cidades continuavam a enfrentar a pobreza também existente no espaço rural. Viam-se em meio a um processo de modernização da agricultura, onde, por um lado, tentavam se inserir no Modo Capitalista de Produção, e por outro, devido a descapitalização, eram forçados a vender a propriedade e migrar. Então aqueles menos afortunados, que já possuíam pouco, mas que tinham seu estabelecimento para produzir seu alimento sentiam-se obrigados a enfrentar as dificuldades independente de sua escolha de permanecer ou não no espaço rural.

A preocupação com as questões ambientais também passam a se fazer presente nas discussões sobre o meio rural. A multifuncionalidade do espaço rural foi, por muito tempo, negligenciada. O espaço rural era percebido apenas pelas atividades agropecuárias e pelo caráter agroexportador, que tinha por objetivo a produção, ficando de lado tanto questões sociais, quanto ambientais. Nos anos mais recentes, sobretudo a partir dos anos de 1990, o meio rural deixa de ser analisado como exclusivamente agrícola.

Novas funções passam a ser desempenhadas pelo meio rural. A visão de atraso e de oposição ao urbano passa a ser lentamente superada. O rural passa a ser compreendido como lugar de oportunidades, de moradia e lazer. Atividades "antigas" ou tradicionais, até então vistas como sem importância, agora tornam-se alternativas de renda e emprego, ganhando em importância econômica e cultural. As consequências desses avanços resultam em transformações mais pontuais, como a integração rural/urbana.

Conforme Candiotto e Corrêa (2008), o espaço rural passa a incorporar características urbanas, e a "industrializar-se". O espaço urbano também passa a assumir características rurais conduzidas por aqueles que o deixaram, através de seus costumes e tradições.

A expansão de atividades não agrícolas ${ }^{10}$ no espaço rural também remete a esse processo de "industrialização". Os atores sociais passam a adotar estratégias de reprodução, buscando inserir atividades não agrícolas em seus estabelecimentos ou até mesmo usando a força de trabalho fora do estabelecimento familiar para aumentar a renda.

Esta análise justifica-se pela forma desigual e seletiva que o Estado viabiliza/ou o desenvolvimento do agronegócio e da agricultura familiar, que merece destaque, pois como será abordado adiante, foi desigual nos anos pós Grande Guerra, culminando com a Revolução Verde em 1970, marginalizando agricultores familiares que se viam fora da agenda política do Estado, estes que mesmo ganhando maior destaque após década de 1990, permanecem recebendo investimentos muito inferiores aos do agronegócio.

Em função disso, este artigo tem por objetivo abordar as transformações históricas pelas quais o espaço rural passou nas últimas décadas, dando destaque às décadas de $1970 \mathrm{e}$ 1990, que são marcadas por transformações socioeconômicas e ambientais e que trouxeram mudanças significativas a ele.

Abordar-se-á ainda neste artigo o papel do Estado brasileiro enquanto mediador dessas transformações, discutindo as estratégias de desenvolvimento rural adotadas nas décadas de 1970 e a partir de 1990. Discutir-se-ão também os impactos sociais que a população rural sofreu

\footnotetext{
10 Por atividades não agrícolas deve-se levar em conta àquelas tarefas (dentro e fora da propriedade) que não implicam o envolvimento direto nos processos de produção vegetal e/ou animal (SCHNEIDER, 2003).
} 


\section{AS TRANSFORMAÇõES RECENTES NO ESPAÇO RURAL BRASILEIRO: ANÁLISES DO PAPEL DO ESTADO NAS POLÍTICAS DE DESENVOLVIMENTO RURAL DAS DÉCADAS DE 1970 A 1990}

devido à entrada do capital e o surgimento de movimentos sociais na luta pela reforma agrária.

\section{MATERIAIS E MÉTODOS}

Para atingir os objetivos propostos buscou-se fazer uma análise sistematizada das transformações do espaço rural nas últimas décadas. Diante disso, considerou-se que a metodologia qualitativa tenha sido a mais adequada para este trabalho em razão da natureza dos objetivos propostos.

“Desse modo, na pesquisa qualitativa é importante a imersão do pesquisador no contexto da interpretação e interação com o objeto estudado e a adoção de postura teóricometodológica para decifrar os fenômenos" (PESSÔA, 2012). Ainda, segundo esse autor, a partir dos resultados alcançados é possível a compreensão da realidade, permitindo-se posicionar criticamente frente a ela. "Por ser uma abordagem mais interpretativa que se propõe traduzir e expressar o fenômeno estudado, também constitui-se em um trabalho laborioso, visto que é necessário registrar as informações, coletar dados, organizá-los e fazer as análises" (MATOS; PESSÔA, 2009).

Diante disso, a metodologia foi organizada em dois momentos. O primeiro baseou-se em pesquisas e leituras principalmente em obras de Maria José Carneiro (1997, 1998), Sergio Schneider (1999, 2001, 2003, 2009), Maria Nazareth Wanderley (2000), Lauro Mattei (2006, 2012), Bernardo Maçano Fernandes (2000 e 2008), Zander Navarro (2001), entre outros. Em um segundo momento houve levantamento, pesquisa e análise de dados secundários, como o Ministério do Desenvolvimento Agrário (MDA), Instituto Brasileiro de Geografia e Estatística (IBGE), Instituto Paranaense de Desenvolvimento Econômico e Social (IPARDES), Sistema IBGE de Recuperação Automática (SIDRA), entre outras instituições e órgão oficiais.

Desta forma, este artigo está dividido em duas seções, sendo a primeira intitulada "as estratégias de desenvolvimento rural" e a segunda "a reestruturação agropecuária e a questão agrária".

\section{RESULTADOS E DISCUSSÕES}

\subsection{AS ESTRATÉGIAS DE} DESENVOLVIMENTO RURAL

A década de 1990 é marcada por ser um momento histórico para a agricultura familiar, que até então era colocada em segundo plano pelo Estado. As estratégias de desenvolvimento rural visavam, sobretudo, a agricultura não familiar. É na década de 1990 que a agricultura familiar passa a receber investimentos por meio de políticas públicas, a exemplo de 1996, quando houve a criação do Programa Nacional de Fortalecimento da Agricultura Familiar (Pronaf $\left.{ }^{11}\right)$. Considerou-se agricultor familiar não como um grupo social homogêneo, mas bastante carregado de diversidade, portanto, um conceito genérico, que incorpora múltiplas situações específicas. LAMARCHE (1998, p. 233) enfatiza ainda que: "um produtor agrícola familiar é aquele que exerce uma atividade produtiva numa unidade de produção agrícola familiar, isto é, numa unidade de produção na qual a propriedade e o trabalho estão estreitamente ligados a família".

No entanto, para discutir-se essa década torna-se necessário contextualizar as mudanças que ocorreram principalmente na década de 1970 que, historicamente, trouxe novos rumos, e uma nova dinâmica ao espaço rural.

Desta forma, a proposta desta seção foi de realizar, através de três subseções, um levantamento das transformações no meio rural conduzidas ao longo das décadas de 1970 e 1990 com objetivo de compará-las. Aborda-se inicialmente a Revolução Verde, considerada o "motor" das transformações no campo e que iniciou-se no Pós-Guerra e consolidou-se na década de 1970. Discutem-se ainda as políticas de desenvolvimento rural promovidas pelo Estado como forma de intervenção direta no

\footnotetext{
${ }^{11}$ Em 1995 foi lançado o Plano Nacional de Fortalecimento da Agricultura Familiar (PLANAF) que, em 1996 transformou-se no Programa Nacional de Fortalecimento da Agricultura Familiar (PRONAF), criado pelo Decreto no. 1.946/96 (CANDIOTTO e CORRÊA, 2004).
} 


\section{NEUMANN,E., FAJARDO,S. e MARIN,M.Z. \\ AS TRANSFORMAÇÕES RECENTES NO ESPAÇO RURAL BRASILEIRO: ANÁLISES DO PAPEL DO ESTADO NAS POLÍTICAS DE DESENVOLVIMENTO RURAL DAS DÉCADAS DE 1970 A 1990}

campo e finaliza-se a seção discutindo as relações entre a década de 1970 e de 1990.

\subsubsection{O MODELO AGRíCOLA TECNOLÓGICO (REVOLUÇÃO VERDE) \\ O final da Segunda Guerra Mundial} culmina com a dispersão do Modo de Produção Capitalista e a consolidação dos Estados Unidos da América como novos líderes mundiais. A partir de então uma nova lógica é inserida no espaço rural. A terra passa a ter maior valor econômico e a modernização da agricultura se faz "necessária" para aumentar a produção. Esse processo substituiria a agricultura tradicional, baseada no uso dos recursos naturais de forma que conciliava a necessidade do agricultor com o tempo de reposição daqueles recursos, por uma agricultura moderna, baseada no uso de técnicas mais avançadas que alteraria a estrutura de produção, com o uso de implementos, insumos agrícolas e motomecanização.

A “substituição" e modificação efetiva-se nos países em desenvolvimento na década de 1970 e com a Revolução Verde. Brum (1983) definiu-a como uma extraordinária revolução tecnológica.

A chamada Revolução Verde foi um programa que tinha por objetivo explícito contribuir para o aumento da produção e da produtividade agrícola no mundo, através do desenvolvimento de experiências no campo da genética vegetal para a criação e multiplicação de sementes adequadas às condições dos diferentes solos e climas e resistentes às doenças e pragas, bem como da descoberta e aplicação de técnicas agrícolas ou tratos culturais mais modernos e eficientes. Deu seus primeiros passos por volta de 1943, ainda durante a 2a Grande Guerra Mundial, quando a vitória para os aliados, sob a liderança dos EUA, já se delineava no horizonte (p. 55).

Na teoria, a Revolução Verde foi um discurso modernizante e promissor. No entanto, além da retórica, pode-se perceber que as modificações que ela efetivou no espaço rural foram muito além das promessas de aumento da produção e da produtividade.
Em decorrência da chamada 'Revolução Verde', a agricultura tradicional, que vigorou até a década de 1970, foi sendo subordinada a um modelo econômico baseado em: tecnologia químico-dependente; ampliação da monocultura; mecanização e intensificação da espoliação de recursos naturais; utilização de bens públicos e de incentivos fiscais; apropriação privada dos lucros e socialização do ônus. Hoje, o Brasil tem sua economia sustentada principalmente pela exportação de commodities agrícolas e minerais (ABRASCO, 2015, p. 591).

O aumento da produção e da produtividade prometido pela Revolução Verde, com o objetivo de combater a fome nos países pobres, era e ainda é usado como discurso, de que a solução para a falta de comida à mesa seria a modernização técnica da agricultura. Tal discurso é um tanto quanto contraditório, pois a modernização deixou os agricultores familiares à margem desse processo, o que levou, entre outros efeitos, ao crescimento do êxodo rural.

Os anos de 1970, no Brasil, passaram a ter uma população urbana maior que a população rural. Muitos agricultores familiares que não conseguiam inserir-se na lógica capitalista vendiam suas propriedades e migravam para as periferias das cidades e aqueles que conseguiam muitas vezes acabavam se endividando, e como consequência, também vendiam suas propriedades.

\subsubsection{INTERVENÇÃO DO ESTADO E NOÇÕES DE DESENVOLVIMENTO RURAL, POLÍTICAS AGRÁRIAS E AGRÍCOLAS.}

O Estado trata de dar garantias para as empresas privadas se instalarem no país, principalmente às multinacionais, para dessa forma, reproduzir a lógica do Modo de Produção Capitalista. Sabe-se que o Estado é um dos agentes da produção do espaço, seja ele rural ou urbano, e tem por objetivo amenizar as diferenças das e entre as regiões.

O Estado é um dos principais agentes na produção do espaço (urbano e rural) como uma totalidade, seja na forma de intervenção 


\section{NEUMANN,E., FAJARDO,S. e MARIN,M.Z. \\ AS TRANSFORMAÇÕES RECENTES NO ESPAÇO RURAL BRASILEIRO: ANÁLISES DO PAPEL DO ESTADO NAS POLÍTICAS DE DESENVOLVIMENTO RURAL DAS DÉCADAS DE 1970 A 1990}

\begin{abstract}
direta ou indireta sempre viabilizando os interesses de ampliação e reprodução do capital nos diferentes territórios. As intervenções públicas foram e ainda são muito comuns no planejamento e gestão do espaço com a finalidade de criar facilidades para reorientação de investimentos do capital público e privado, buscando, dessa forma, amenizar as diferenças entre regiões e lugares que são inerentes ao modo capitalista de produção (ALENCAR; MENEZES, 2009, p.122123).
\end{abstract}

Com base nisso é que aborda-se a seguir as estratégias de desenvolvimento rural adotadas nos anos de 1970 e os impactos sobre o meio rural.

É importante destacar que na década de 1970 a sociedade vivia em um Estado desenvolvimentista centralizador. Segundo Rückert (2005), o Estado desenvolvimentista brasileiro implementa a partir de 1940 um núcleo de consenso desenvolvimentista análogo ao keynesianismo europeu. De corte explicitamente geopolítico no Pós-1964, o Estado autoritário brasileiro é um dos maiores exemplos de projeto desenvolvimentista de corte cepalino.

Além de se analisar o momento histórico, é preciso compreender também as diferentes concepções de políticas de desenvolvimento rural, pois há um conjunto de expressões que muitas vezes se confundem, mas que possuem significados distintos.

Neste sentido, a primeira expressão é desenvolvimento agrícola (ou agropecuário). Aqui estaria se referindo exclusivamente às condições da produção agrícola e/ou agropecuária, suas características, no sentido estritamente produtivo, identificando suas tendências em um período de tempo dado. Refere-se, portanto, à base propriamente material da produção agropecuária, suas facetas e evolução - por exemplo, área plantada, produtividade, formatos tecnológicos, economicidade, uso do trabalho como fator de produção, entre outros tantos aspectos produtivos (NAVARRO, 2001, p. 86).
Nesse sentido, compreende-se a política agrícola restrita a produção, voltada para o aperfeiçoamento de técnicas e equipamentos direcionados à produtividade agrícola. Para Navarro:

Esse período [pós-Segunda Grande Guerra], que coincide com a impressionante expansão capitalista dos 'anos dourados' (1950-1975), é assim um divisor de águas também para as atividades agrícolas, e o mundo rural (re) nasceria fortemente transformado, tão logo os efeitos desta época de transformações tornaram-se completos. A noção de desenvolvimento rural, naqueles anos, certamente foi moldada pelo 'espírito da época', com o ímpeto modernizante (e seus significados e trajetórias) orientando também as ações realizadas em nome do desenvolvimento rural (2001, p. 84).

O Estado objetivava a modernização da agricultura. Reproduzindo o capital no espaço rural, implantou políticas de "desenvolvimento" que priorizaram o setor agrícola, a fim de aumentar a produtividade e a renda de alguns agricultores. "O projeto de desenvolvimento rural adotado ao longo de décadas no país tem como principal objetivo a expansão e consolidação do agronegócio, tendo alcançado resultados positivos, sobretudo em relação ao aumento da produtividade e à geração de divisas para o país via exportação. No entanto, esta opção tem implicado custos sociais e ambientais crescentes" (MARQUES, 2002, p. 96).

O objetivo do Estado era que, ao criar-se subsídio para o aumento da produção e da produtividade, haveria o aumento da renda, o que resultaria em melhores condições de vida para os agricultores. Assim, concedia crédito com juros baixos, estimulando os agricultores a adquirirem "pacotes tecnológicos" para suas atividades agrícolas. No entanto, os problemas existentes no espaço rural não se restringiam apenas a questões econômicas, como se observará a seguir. Por sua vez, o desenvolvimento agrário: 


\section{AS TRANSFORMAÇÕES RECENTES NO ESPAÇO RURAL BRASILEIRO: ANÁLISES DO PAPEL DO ESTADO NAS POLÍTICAS DE DESENVOLVIMENTO RURAL DAS DÉCADAS DE 1970 A 1990}

\begin{abstract}
Refere-se a interpretações acerca do 'mundo rural' em suas relações com a sociedade maior, em todas as suas dimensões, e não apenas à estrutura agrícola, ao longo de um dado período de tempo. Quase sempre 'metanarrativas', estudam as mudanças sociais e econômicas no longo prazo, reivindicando uma aplicação de modelos teóricos entre países e regiões. Sob tal expressão, as condições próprias da produção (o desenvolvimento agrícola) constituem apenas uma faceta. A análise centra-se usualmente também nas instituições, nas políticas do período, nas disputas entre classes, nas condições de acesso e uso da terra, nas relações de trabalho e suas mudanças, nos conflitos sociais, nos mercados, para citar alguns aspectos. Portanto, a 'vida social rural' e sua evolução adentram tais
\end{abstract}

análises em todos os seus aspectos (NAVARRO, 2001, p. 86).

Seguindo o pensamento do autor, o desenvolvimento agrário refere-se, de modo geral, as distintas dimensões que relacionam-se ao acesso e uso do estabelecimento agropecuário, envolvendo, sobretudo, as políticas de reforma agrária, ponto crucial para os problemas do espaço rural. A concentração de terras sempre existiu no espaço rural brasileiro e teve início ainda no Brasil colônia com a política de doação de terras, as Sesmarias, instituída em 1530. O Quadro 1 demonstra a distribuição das terras entre agricultores familiares e não familiares.

Quadro 01 - Número e Área dos estabelecimentos agropecuários - Brasil - 2006. Fonte: IBGE, Censo agropecuário (2006). Org.: Autor (2016)

\begin{tabular}{|c|c|c|c|c|}
\hline BRASIL & No Estabelecimentos & $\%$ & Área (ha) & \% \\
\hline Agricultura familiar & 4.366 .267 & 84 & 80.102 .694 & 24 \\
\hline Agricultura não familiar & 809.369 & 16 & 253.577 .343 & 76 \\
\hline TOTAL & 5.175 .636 & 100 & 333.680 .037 & 100 \\
\hline
\end{tabular}

O quadro 1 demonstra a desigual distribuição de terras, no Brasil. Ao analisar-se, o caso brasileiro, o número de estabelecimentos da agricultura familiar é representada por $84 \%$ (4.366.267 estabelecimentos), enquanto a agricultura não familiar por 16\% (809.369). Entretanto, apesar da predominância de estabelecimentos agropecuários da agricultura familiar os mesmos estão distribuídos em apenas 24\% (80.102.694 hectares) do total de terras, e, em contrapartida a agricultura não familiar conta com 76\% (253.577.343 hectares) do total de terras, mesmo tendo minoria dos estabelecimentos, o que representa a concentração fundiária intensificada com a modernização da agricultura. Esses poucos estabelecimentos agropecuários ocupando extensas áreas acentuam as desigualdades no espaço rural, deixando aos agricultores familiares, pequenas áreas para cultivo.

A partir disso, compreende-se a década de 1970 como divisora de águas para os agricultores familiares. O problema da desigual distribuição de terras se combinava com famílias numerosas. Consequentemente a agricultura tradicional entrou em crise, devido, entre outros motivos, à intensificação do uso e ao esgotamento da fertilidade do solo. Diante desse cenário e motivado pela expansão da modernização da agricultura, houve a redução das atividades agrícolas tradicionais, culminando com a falência de muitos agricultores familiares e no aumento considerável do êxodo rural ainda na década de 1970. É com base nisso que se afirma que a política de desenvolvimento agrícola da época era seletiva e excludente, beneficiando quem detinha o capital, e por consequência, o poder. 


\section{NEUMANN,E., FAJARDO,S. E MARIN,M.Z. \\ AS TRANSFORMAÇÕES RECENTES NO ESPAÇO RURAL BRASILEIRO: ANÁLISES DO PAPEL DO ESTADO NAS POLÍTICAS DE DESENVOLVIMENTO RURAL DAS DÉCADAS DE 1970 A 1990}

Se as políticas de desenvolvimento agrícola não correspondem aos anseios dos mais necessitados e as de desenvolvimento agrário não acontecem da forma como deveriam, cabe a discussão da emergência de uma eficiente política de desenvolvimento rural.

A definição do que seja exatamente 'desenvolvimento rural' [...] tem variado ao longo do tempo, embora normalmente nenhuma das propostas deixe de destacar a melhoria do bem-estar das populações rurais como o objetivo final desse desenvolvimento (adotando indicadores de ampla aceitação). As diferenças, portanto, surgem nas estratégias escolhidas, na hierarquização dos processos (prioridades) e nas ênfases metodológicas. Além disso, certamente tais diferenças são fundamentadas em leituras de realidades (interpretações) distintas apontando objetivos igualmente distintos, ou seja, a análise do que tenha sido exatamente o desenvolvimento agrário fundamentará leituras (e projetos) correspondentes de desenvolvimento rural. Apenas como rapidíssimo exemplo: desenvolvimento rural, nos anos 70, necessariamente incluiria a intensificação tecnológica e a crescente absorção de insumos modernos pelos produtores, como parte de uma estratégia de aumento da produtividade e, como objetivo finalístico, a elevação da renda dos produtores. Em nossos dias, face à queda real dos preços recebidos pelos produtores e à virtual ausência de sistemas de ação governamental ao longo de tantos anos (especialmente a redução do financiamento), aqueles seriam componentes que poderiam se repetir sob a mesma forma? O conceito de desenvolvimento rural, em consequência, altera-se também ao longo do tempo, influenciado por diversas conjunturas e, principalmente, pelos novos condicionantes que o desenvolvimento mais geral da economia e da vida social gradualmente impõem às famílias e às atividades rurais (NAVARRO, 2001, p. 88).

O desenvolvimento rural representa a integração da política agrária com a agrícola. $\mathrm{O}$ conceito de rural remete-nos a noção de espaço, portanto, um verdadeiro desenvolvimento só acontecerá a partir do momento que a política tenha por objetivo resolver os problemas do rural a partir de todas suas dimensões, tanto ambientais, fundiárias, sociais, quanto econômicas, e não somente uma como quando analisamos a já citada política de desenvolvimento agrícola, que ao invés de amenizar os problemas, apenas os intensifica (problemas ambientais, sociais e a concentração de terras).

\subsubsection{UMA NOVA DÉCADA. NOVOS DESAFIOS}

A década de 1990 inicia-se com problemas semelhantes se não os mesmos da década de 1970. A concentração fundiária permanece, o agricultor familiar continua marginalizado e políticas de desenvolvimento agrícola ainda são vistas como de desenvolvimento rural. No entanto, o momento histórico é outro. A constituição de 1988 consolida transformações político-institucionais. Tais mudanças exigem a necessidade de compreender a descentralização do Estado como uma redistribuição de poder e de recursos, responsabilidades e espaços de decisão. A sociedade civil ganha destaque com a reforma do Estado, onde sua participação na criação e supervisão de políticas públicas ganha em importância, ou seja, o Estado transfere parcelas de seu poder/responsabilidades para a sociedade civil.

A flexibilização dos lugares, com economias mais flexíveis e territórios nacionais inserindo-se no processo de globalização financeira e dos mercados, levam a processos de descentralização política do Estado, que "reorganiza" e reatualiza suas políticas internas e externas. Esses fatores levam ao que ficou conhecido convencionalmente como a reforma do Estado.

A crise do nacional-desenvolvimentismo e do planejamento centralizado; as redefinições da geopolítica clássica que perde seus sentidos originais; a tendência às economias flexíveis e à flexibilização dos lugares, pela alta mobilização do capital e a inserção subordinada dos territórios nacionais periféricos no processo de globalização financeira e de mercados, e a 


\section{AS TRANSFORMAÇÕES RECENTES NO ESPAÇO RURAL BRASILEIRO: ANÁLISES DO PAPEL DO ESTADO NAS POLÍTICAS DE DESENVOLVIMENTO RURAL DAS DÉCADAS DE 1970 A 1990}

\begin{abstract}
emergência dos processos políticos descentralizantes na face do processo de redemocratização conduzem os Estados do Sul, como um todo e, especialmente os latinoamericanos como o Brasil, a reatualizar em suas políticas externas e internas e a requalificar em suas opções e necessidades de ordenação territorial e de desenvolvimento (RUCKERT, 2005, p. 80).
\end{abstract}

Dessa forma, a década de 1990 fica marcada pelo processo de globalização financeira, de industrialização flexível, desregulamentações de mercados, investimentos e desinvestimentos. Estes e outros fatores provocaram a criação de um novo cenário.

"Em primeiro lugar, o processo de reestruturação produtiva tomou um novo impulso após a recessão da economia mundial no período 1990-92. Essa reestruturação produtiva tem-se manifestado por meio de uma nova onda de aquisições e fusões em escala global, envolvendo operações transfronteiriças" (GONÇALVES, 1999, p. 83).

Assim o Estado passa a atribuir novos papeis para a agricultura familiar e ao espaço rural:

A partir dos anos 90 do século passado, as políticas públicas continuam a ter um enfoque setorial com duas vertentes distintas: uma voltada para a agricultura familiar e outra com ênfase no agronegócio. A primeira é uma tentativa do Estado, através de orientações de agências públicas e de capital misto, a exemplo do Banco Mundial, de promover a reprodução do capital, inserindo o camponês ${ }^{12}$ no mercado com a denominação de agricultor familiar. Para isso, desenvolvem Programas que através do crédito, busca a modernização da agricultura familiar, tornando-a competitiva para o mercado (ALENCAR; MENEZES, 2009, p.139).

\footnotetext{
12 Não é objetivo adentrar no debate entre agricultor familiar e camponês. Sugere-se a leitura de Deponti (2007), que contextualiza as perspectivas camponesa, marxista clássica e neomarxista. Ressalta-se que o embasamento para definição de agricultor familiar é Lamarche (1993) e a lei no 11.326/2006 da agricultura familiar.
}

“O surgimento do Pronaf é um marco na intervenção do Estado na agricultura brasileira, porque representa a incorporação efetiva dos agricultores familiares às políticas para o espaço rural" (GAZOLLA e SCHNEIDER, 2013).

A criação do Pronaf em 1996 com o objetivo de "fortalecer" a agricultura familiar busca financiar a produção. "O Programa começou em 1995/96, com quatro áreas de atuação básicas: no financiamento do custeio e investimento agrícolas; fornecimento de infraestrutura rural; negociação e articulação de políticas públicas e formação de técnicos extensionistas e agricultores" (GAZOLLA e SCHNEIDER, 2013).

Isso mostra que as políticas públicas continuam de cunho agrícola/produtivo, semelhantes as da década de 1970, e que o próprio Pronaf é uma política compensatória, que visa amenizar a falta de uma de cunho agrário, ou melhor, de uma ampla e completa reforma agrária.

"Disso decorre, que no Brasil não houve política pública voltada para o espaço rural e sim para as atividades agrícolas. As políticas agrícolas apresentadas pelos dois últimos governos brasileiros, Planaf e Pronaf, como instrumentos de transformação do espaço rural do país não conseguiram dar solução aos problemas decorrentes da excludente estrutura agrária brasileira" (ALENCAR e MENEZES, 2009, p. 145).

Entre autores que tecem suas críticas ao Pronaf destaca-se aqui Mattei (2006a), no trabalho "dez anos de Pronaf: síntese da produção e do debate acadêmico sobre o programa", abrangendo as diferentes modalidades do programa no período 1996 a 2006. Esse estudo, realizado para a Secretaria da Agricultura Familiar (SAF-MDA), aponta limitações do Programa, sendo uma das principais o viés produtivista, que incentiva o uso de insumos modernos. Mattei (2006a), ainda constata no mesmo trabalho que o crédito vem favorecendo a produção agropecuária, concentrando-se em poucas culturas, como a soja, o milho e o feijão. 


\section{NEUMANN,E., FAJARDO,S. e MARIN,M.Z. \\ AS TRANSFORMAÇÕES RECENTES NO ESPAÇO RURAL BRASILEIRO: ANÁLISES DO PAPEL DO ESTADO NAS POLÍTICAS DE DESENVOLVIMENTO RURAL DAS DÉCADAS DE 1970 A 1990}

Gazolla e Schneider (2013), discutem a necessidade do Pronaf dar "um passo à frente", enquanto política, a fim de corresponder aos reais anseios da agricultura familiar:

[...] o Programa necessita dar 'um passo à frente' em sua evolução política e ajustar o foco nas reais necessidades da agricultura familiar em suas várias dimensões, como nas questões ambientais, nas estratégias coletivas das famílias, o fomento às suas pequenas atividades econômicas e produtivas, incentivos à produção de alimentos (o seu autoconsumo, que está relacionado à segurança alimentar e nutricional), incorporar as atividades rurais não agrícolas e financiar empreendimentos que fortaleçam a célula básica da agricultura praticada em pequena escala - a família ( $p$. 64).

No entanto, por mais que o foco do "desenvolvimento rural" continue sendo o agrícola, como evidenciado no Pronaf, a década de 1990 deve ser compreendida como um momento de avanços para os agricultores familiares. A sociedade civil organiza-se e leva à luz a discussão dos problemas e interesses coletivos, tendo um pouco mais de poder de decisão nas políticas de desenvolvimento. Esta participação, por exemplo, pode ser observada nos Conselhos Municipais de Desenvolvimento Rural e nos Territórios Rurais e da Cidadania, ambos, Programas do Governo Federal. O Pronaf, independente de seu viés produtivista, merece destaque como grande conquista das lutas dos agricultores familiares, como apontam Gazolla e Schneider:

Desde o surgimento do Pronaf, em 1996, o Programa se transformou e trouxe inquestionáveis efeitos positivos ao desenvolvimento rural brasileiro, tais como contribuir para melhorar as condições de produção e segurar os agricultores no campo, aumentar a oferta de alimentos, aumentar a produtividade de alguns produtos, gerar ocupação e empregos, que se refletem positivamente em alguns indicadores econômicos e produtivos rurais, entre outros efeitos benéficos que os estudos têm destacado (2013, p. 63).

Analisando as políticas públicas do pósdécada de 1990, e as de 1970, percebe-se que o Estado atuou de forma a garantir o desenvolvimento capitalista, intervindo de diferentes formas, desempenhando um papel regulador na organização espacial. Portanto, o capital territorializou-se no espaço rural brasileiro, por meio da intervenção estatal, tanto de forma direta como de forma indireta.

Nota-se que o estímulo ao aumento da produção e da produtividade ainda se fazem presentes no espaço rural, e políticas agrícolas incentivam a inserção do agricultor no "pacote tecnológico", atualmente dando ênfase não apenas aos agricultores não familiares (agronegócio), mas também aos agricultores familiares. Comprova-se que o cenário mudou, mas o foco continua o mesmo, isto é, de expandir as relações capitalistas de produção no campo. Ou seja, se até a década de 1990 o Estado visava financiar/promover grandes empresários rurais, atualmente ele visa criar "pequenos empresários".

\subsection{A REESTRUTURAÇÃO AGROPECUÁRIA E A QUESTÃO AGRÁRIA}

A reestruturação de cunho econômico produtivo/agrícola do espaço rural brasileiro a partir da década de 1970, permitiu, via integração entre agricultura e indústria, a consolidação dos Complexos Agroindustriais CAls - e, por conseguinte, o agronegócio. As políticas públicas daquela época apontavam para a modernização da agricultura, por meio de financiamentos, pesquisa e extensão rural, com o objetivo de ampliar a produção agrícola para a exportação.

Já em um segundo momento, a partir da década de 1990, as questões sociais passam a ganhar força com a atuação dos movimentos sociais, até então reprimidos, especialmente pela ditadura militar. Eles voltam a atuar e se multiplicam com a redemocratização do país e posteriormente com a descentralização e 


\section{AS TRANSFORMAÇÕES RECENTES NO ESPAÇO RURAL BRASILEIRO: ANÁLISES DO PAPEL DO ESTADO NAS POLÍTICAS DE DESENVOLVIMENTO RURAL DAS DÉCADAS DE 1970 A 1990}

redistribuição de funções entre as esferas administrativas.

Desta forma aborda-se nesta seção, mesmo que de forma breve, o surgimento e expansão do agronegócio a partir da consolidação dos CAls na segunda metade do século XX. Aborda-se também o surgimento de movimentos sociais e suas conflitualidades com o agronegócio, finalizando a seção com as consequências da modernização da agricultura.

\subsubsection{A DESARTICULAÇÃO DOS COMPLEXOS RURAIS E CRIAÇÃO DOS COMPLEXOS AGROINDUSTRIAIS - CAIS}

A modernização da agricultura brasileira iniciou-se na região Sul do Brasil ainda na década de 1940 , com a cultura do trigo e posteriormente da soja. No entanto, foi na década de 1970 e com a intensa intervenção do Estado que ocorreu a integração da indústria com a agricultura, garantindo a expansão do capital no campo. Novas dinâmicas e fenômenos emergem como consequência, a exemplo da crise do Complexo Rural que tinha como características a utilização de instrumentos e técnicas de trabalho simples, herdadas de geração a geração; uma forte ligação com a terra; e a economia tinha uma dinâmica local/regional. "O complexo rural passou a ser substituído pelos CAls, definidos como um conjunto de atividades econômico-agrícolas, industriais, comerciais e financeiras - que representam alto grau de integração entre si" (BRUM, 1983). Ou seja, tem como característica um conjunto de novos métodos e técnicas, com foco totalmente produtivista.

“A partir de meados da década de 1970, a agricultura e todo o setor agrário, passa a receber maior atenção por parte de políticas públicas. 0 crédito e os financiamentos agrícolas ampliamse. A explicação pode ser encontrada na própria constituição de um modelo de modernização no campo caracterizado pelo surgimento do complexo agroindustrial" (FAJARDO, 2008, p. 74).

Além de o Estado ter agido como financiador da modernização da agricultura, ele foi responsável também pela implantação de uma logística no território nacional a qual garantiu a realização e a circulação da produção.

A expansão dos Complexos Agroindustriais (CAIs) ocorreu devido à incorporação de vastas extensões de terra, no caso da soja e das cadeias produtivas de origem histórica como o café, o algodão, a pecuária bovina, com a utilização de tecnologia, da mecanização da produção, prioritariamente voltada para a exportação. Os complexos agroindustriais são formados a partir da introdução da lógica capitalista no campo, capaz de transformar a produção agrícola em agronegócio (industrialização da agricultura). Foram incorporados ao processo produtivo, tratores, colheitadeiras, produtos químicos e sementes selecionadas, cuja produção foi orientada para uma demanda de origem urbana e industrial. Esse é o caso da produção de soja, laranja, café, cana de açúcar, entre outros produtos (MARAFON, 2011, p. 74).

Após o surgimento e consolidação dos CAls o conceito de agronegócio, especificamente na década de 1990, consolida-se por meio da Associação Brasileira do Agronegócio - Abag.

[...] se populariza no Brasil o termo agronegócio (tradução literal do termo inglês agribusiness) cujo sentido designa, a princípio, um conjunto de ações ou transações comerciais (produção, industrialização e comercialização), ou seja, negócios relacionados à agricultura e à pecuária. Como o termo foi cunhado para o contexto agropecuário norte-americano, a tradução do conceito trouxe, desde o início, a carga do modelo, designando um conjunto de atividades agropecuárias em grande escala desenvolvidas em grandes extensões de terra (mesmo a base sendo o family farming norte-americano) (SAUER, 2008, p.14).

Visto que:

A apropriação do conceito agronegócio, materializado na constituição da Abag, no início dos anos 1990, visava construir uma representação do setor patronal rural como moderno, tecnificado e eficiente. Representação distante e diferente da 


\section{NEUMANN,E., FAJARDO,S. E MARIN,M.Z. \\ AS TRANSFORMAÇÕES RECENTES NO ESPAÇO RURAL BRASILEIRO: ANÁLISES DO PAPEL DO ESTADO NAS POLÍTICAS DE DESENVOLVIMENTO RURAL DAS DÉCADAS DE 1970 A 1990}

construída, por exemplo, pela ação política da Frente Ampla da Agropecuária Brasileira, caracterizada como profundamente corporativa e voltada, exclusivamente, para interesses territoriais (defesa incondicional da propriedade da terra) dos grandes proprietários; e, portanto, avessa a qualquer processo de democratização e modernização da estrutura fundiária (SAUER, 2008, p. 24-25).

Nos anos de $1980{ }^{13}$ devido ao crescimento da dívida externa ${ }^{14}$, a estratégia adotada pelo Estado foi fortalecer o agronegócio para equilibrar a balança comercial, por meio de exportações agrícolas.

Nesse período, numa tentativa de reequilibrar a balança de pagamentos, as importações foram ainda mais contidas e as exportações por outro lado incentivadas, embora a presença de medidas, herdadas ainda do período de substituição de importações, onde tanto importações quanto exportações eram restringidas para dar sustentação ao processo de industrialização, inibiam uma maior inserção das exportações nacionais (REZENDE, 1989, p. 63).

A agenda política investe no espaço rural de forma a aumentar a produtividade, para garantir a elevação do Produto Interno Bruto PIB e para inserir-se internacionalmente, o que novamente levou ao aumento da pobreza e da desigualdade no campo, pois a preocupação do Estado era com um "desenvolvimento ${ }^{15}$ " embasado na modernização, sobretudo, econômica ${ }^{16}$ do país e não em um

\footnotetext{
${ }^{13}$ Durante a década de 1980, a agricultura foi o único setor responsável por saldos positivos nas exportações (MELO, 1993).

${ }^{14}$ A partir de 1980 a economia brasileira entra em período de recessão. Dívida externa, inflação, déficit na balança de pagamentos foram alguns ingredientes do período (BRAUN, 2004).

15 Há muitas controvérsias em torno do conceito de desenvolvimento. Não raramente, conceitos como progresso, crescimento, industrialização, modernização, têm sido utilizados como sinônimos de desenvolvimento (ALMEIDA e NAVARRO, 1997).

${ }^{16}$ Para Almeida e Navarro (1997), a ideia de desenvolvimento ganha força no início do século XX, revigorada por teorias e
}

desenvolvimento amplo. Para Oliveira (2002), os significativos avanços do Pós-Guerra, em todas as áreas da Ciência, não foram acompanhados de um desenvolvimento (no sentido amplo do seu termo, isto é, melhoria da qualidade de vida) junto a todas as nações do mundo.

Com a consolidação dos CAls e a ascensão do agronegócio, a monocultura expandiu-se ainda mais no espaço rural brasileiro. Somados a isso a crise do petróleo e a necessidade de se buscar alternativas para resolver o problema da energia/combustível, o campo transformou-se também em território de produção de agroenergia, processadas da cultura do milho e da cana de açúcar, para a produção do etanol, acentuando cada vez mais o êxodo rural, e aumentando o "cinturão de pobreza" nas cidades.

\subsubsection{MOVIMENTOS SOCIAIS $X$ AGRONEGÓCIO}

A década de 1990, por um lado, é marcada pela abertura comercial da economia, que afeta os agricultores familiares que até então, eram parcialmente excluídos das políticas creditícias. Assim, as reivindicações dos trabalhadores rurais, que já haviam começado a ter voz na Constituição de 1988, ganharam destaque nas "Jornadas Nacionais de Luta" da primeira metade da década de noventa, que a partir de 1995 passaram a ser denominadas de "Gritos da Terra Brasil" (SCHNEIDER; CAZELLA; MATTEI, 2004, p. 2). Ocupou-se assim, de vez, a agenda pública do meio rural.

Por outro lado, o modelo agroexportador foi ampliado por corporações nacionais e transnacionais. Assim, a década de 1990 traz consigo a conflitualidade entre agronegócio e movimentos sociais.

$\mathrm{Na}$ primeira década do século XXI, essas mudanças conjunturais da questão agrária geraram diferentes conflitualidades. Os movimentos camponeses passaram a se

princípios econômicos que viam no Estado um dos impulsionadores da modernização, garantindo um importante papel ao desenvolvimento econômico e técnico 


\section{AS TRANSFORMAÇÕES RECENTES NO ESPAÇO RURAL BRASILEIRO: ANÁLISES DO PAPEL DO ESTADO NAS POLÍTICAS DE DESENVOLVIMENTO RURAL DAS DÉCADAS DE 1970 A 1990}

\begin{abstract}
confrontar cada vez mais com corporações transnacionais e cada vez menos com latifúndios. Esta confrontação está associada ao processo de globalização da questão agrária com a territorialização das corporações transnacionais para vários países e da criação de uma organização mundial de movimentos camponeses, a Via Campesina. A crise alimentar demonstrou $\mathrm{O}$ mito de que $\mathrm{o}$ agronegócio seria o grande produtor de alimentos, destacando a participação do campesinato e a necessidade de políticas de soberania alimentar. $\mathrm{O}$ aumento do preço do petróleo e a ampliação da produção de agrocombustíveis transformaram o campo em território para a produção de agroenergia e de alimentos. O MST e mais de noventa outros movimentos camponeses brasileiros estão no centro destas conflitualidades da atual questão agrária (FERNANDES, 2008, p. 2).
\end{abstract}

Com relação à Reforma Agrária, a Constituição brasileira de 1988:

[...] introduziu importantes mudanças na ordem legal, como a possibilidade de desapropriação das terras para fins de reforma agrária que não cumprissem sua função social. Além disso, também foi aprovada, no início da década de 1990, a Lei Agrária, que fixa novos parâmetros legais para a execução dos programas de reforma agrária (MATTEI, 2012, p. 315).

"No entanto, mesmo com os aparatos legais à disposição, o Estado, na época, não destinou atenção política para o tema, o que explica o baixo índice de assentamentos realizado" (MATTEI, 2012).

Em meio às lutas sociais antecedentes a Constituição de 1988 surgiu alguns movimentos sociais, com destaque ao Movimento dos Trabalhadores Rurais Sem Terra - MST. O Movimento foi fundado, segundo Fernandes (2008), em 1984, quando foi realizado seu primeiro encontro, na cidade de Cascavel, Estado do Paraná. "Todavia, ao considerar-se o seu período de gestação (a "pré-história" do MST) a partir das primeiras lutas e das primeiras reuniões, reportamo-nos aos anos de 1978 a 1983" (FERNANDES, 2000).

O MST é resultado da organização e da resistência dos camponeses contra o processo agroindustrial que "industrializa" a agricultura por meio do agronegócio e tem como característica a luta pela terra e pela reforma agrária. "Anterior ao MST, em 1963, foi fundada a Confederação Nacional dos Trabalhadores na Agricultura - Contag, reconhecida pelo decreto-lei no 53.517, de 31 de janeiro de 1964" (SILVA, 2013).

“A Contag é uma entidade sindical que representa os trabalhadores rurais a nível nacional, considerada a maior confederação com o propósito de representar os trabalhadores no Brasil" (RICCl, 1999). Segundo o mesmo autor, a Contag, é considerada também um dos principais resultados políticos das lutas sociais que ocorreram no campo brasileiro nos anos de 1960.

Sua importância ainda merece destaque por ter sido responsável por manter os movimentos sociais rurais de luta no campo mesmo no período da ditadura militar. "É importante assinalar que foi nesse período que houve a implantação de um modelo de desenvolvimento agropecuário com o objetivo de acelerar a modernização da agricultura, com base na grande propriedade" (FERNANDES, 2000).

Essas novas dinâmicas que surgem no espaço rural devem-se a essas profundas transformações que o mesmo sofreu, inicialmente com a entrada do capital estrangeiro explorando as riquezas naturais através da retirada da mata nativa, para plantio de extensas áreas de pastagem ou para o desenvolvimento do agronegócio, afetando a biodiversidade local e, posteriormente, a valorização da terra por meio da acumulação de capital. A terra passa a ser vista como mercadoria, e tem em seu seio a modernização da agricultura que produz grandes mudanças no espaço rural.

\subsubsection{IMPACTOS SOCIOAMBIENTAIS DECORRENTES DA MODERNIZAÇÃO DA AGRICULTURA BRASILEIRA}




\section{NEUMANN,E., FAJARDO,S. E MARIN,M.Z. \\ AS TRANSFORMAÇÕES RECENTES NO ESPAÇO RURAL BRASILEIRO: ANÁLISES DO PAPEL DO ESTADO NAS POLÍTICAS DE DESENVOLVIMENTO RURAL DAS DÉCADAS DE 1970 A 1990}

“O modelo de produção agrícola atualmente hegemônico no Brasil, marcado pela entrada do capitalismo no campo e pela Revolução Verde que Ihe da sustentação, revelase perverso em seu modo de apropriação/exploração/expropriação da natureza e da força de trabalho" (ABRASCO, 2015). Nesse sentido, segundo Marques (2002), os impactos provocados pela expansão e consolidação do agronegócio no espaço rural brasileiro geraram profundas transformações, principalmente nas dimensões social e ambiental.

A modernização da agricultura no Brasil aprofundou a concentração de terras, levando tanto a migração de milhares de pequenos proprietários, parceiros, arrendatários e colonos para áreas de expansão da fronteira agrícola, nas regiões Centro-Oeste e Norte, quanto ao êxodo rural para os centros urbanos mais industrializados. Assim, o incremento do pacote tecnológico da Revolução Verde resultou no agravamento de diversos problemas sociais e ambientais, que a história do desenvolvimento da agricultura no país perpetuava, assumindo a forma de modernização conservadora (HESPANHOL, 2008b).

Em relação aos impactos sociais:

Em decorrência da modernização da agricultura, também houve transformação nos processos de formações sociais, culturais e territoriais. Alguns grupos sociais foram deslocados dos seus lugares de origem em decurso da expansão do agronegócio, confirmando a expulsão de grupos tradicionais de suas terras, como quilombolas, populações ribeirinhas e tradicionais, para a chegada de outros grupos (migrantes), tudo em prol da economia e do desenvolvimento. Como se os grupos tradicionais pudessem ser simplesmente transferidos de lugar (MAIA, 2012, p.14-15).

Dessa forma, o processo de modernização traz consigo um desenvolvimento apenas em benefício da reprodução do capital, que intensifica a expropriação daqueles que residiam e tiravam da terra apenas o essencial para sobreviver. É excludente por ser seletivo, ou seja, nem todos tem acesso à modernização, e aqueles que tiveram por meio de incentivos governamentais muitas vezes acabaram por endividar-se. Outro aspecto negativo da modernização é o aumento dos conflitos, tanto entre o agronegócio e a agricultura familiar, como entre os próprios agricultores familiares. Aumentou a violência no campo contra povos tradicionais, posseiros e extrativistas que não possuem a documentação das terras. De um lado gerou desemprego acarretado pela entrada de equipamentos que substituem a mão de obra. De outro, precarizou as relações de trabalho e intensificou a exploração do trabalho.

Somados a isso, o agronegócio propicia também o aumento da concentração fundiária.

Em suma, o agronegócio instrumentalizou na sociedade brasileira um complexo de influências que abrange as dimensões econômica, política e ideológica. Economicamente o agronegócio conta com o incentivo do Estado e das políticas governamentais que viabiliza créditos e infraestrutura para os produtores, além da participação do capital internacional e dos capitais privados que contribuíram para o aumento dessa lógica modernizadora que é o agronegócio. Politicamente o agronegócio se afirma agrupando uma rede de parlamentares, com a finalidade de fortalecer a representação e institucionalização dos próprios interesses, alterando legislações, aprovando medidas governamentais e projetos favoráveis ao setor do agronegócio, construindo uma certa hegemonia. E ideologicamente, os representantes do agronegócio se dizem detentores de um novo modelo de desenvolvimento capitalista que atende aos interesses e as necessidades de todos. Os representantes patronais procuram legitimar esse poder frente à sociedade política e a sociedade civil. Investindo nos lugares midiáticos para ampliar as estratégias comerciais, propagandas e vendas dos seus produtos (MAIA, 2012, p. 20). 


\section{AS TRANSFORMAÇÕES RECENTES NO ESPAÇO RURAL BRASILEIRO: ANÁLISES DO PAPEL DO ESTADO NAS POLÍTICAS DE DESENVOLVIMENTO RURAL DAS DÉCADAS DE 1970 A 1990}

Ou seja, além de promover a intensificação da concentração de terras, o agronegócio ainda tem o apoio estatal, visto que o agronegócio tem por objetivo o aumento da produtividade e consequentemente a reprodução do capital, que "promove o desenvolvimento econômico do país". Dessa forma, atendendo ao interesse do capital, o Estado não dá atenção que merece às políticas de reforma agrária, pois implantá-las iria contra seu papel de reprodutor do capital no espaço.

"Com relação aos impactos ambientais, os mesmos são intensos, principalmente devido ao uso do agrotóxico. Inicialmente extensas áreas de mata nativa são derrubadas, dando início ao processo de degradação dos solos" (BARRETO e RIBEIRO, 2008). O processo de degradação do solo provocado pelos agrotóxicos inicia-se com a esterilização - eliminação de flora e fauna -, que, associada aos processos erosivos, leva a maior demanda por aplicação de produtos químicos. Segundo Romeiro e Abrantes (1981), a deficiência de micronutrientes, ocasionada pela perda de atividade biológica no solo, afeta a qualidade das plantas, tornando-as suscetíveis as pragas. Desta forma, demanda de doses cada vez maiores e/ou diversificadas de agrotóxicos, encerrando assim o ciclo da contaminação do solo.

Assim, a biodiversidade dos lugares é alterada. Os solos, antes férteis, agora são diretamente poluídos por agroquímicos usados para a garantia de uma safra sem pragas e sem grandes perdas.

O uso do agrotóxico traz também consequências à saúde da população que consome os alimentos contaminados, como também ao produtor que manuseia os "defensivos agrícolas ${ }^{17 " .}$

17 Por ironia da lógica capitalista, os agrotóxicos, denominados pelos empresários rurais de defensivos agrícolas, são produtos do campo das ciências da vida, ainda que, paradoxalmente, "combater as pragas" signifique destruir a biodiversidade. Na raiz do uso de agrotóxicos está o modelo econômico capitalista cuja racionalidade fundamenta o uso massivo de venenos no âmbito de uma permissividade que destrói a vida em nome do combate as pragas e do controle de doenças na agricultura (ABRASCO, 2015).
A estratégia de justificar a necessidade dos agrotóxicos é exercida por meio da imposição da racionalidade tecnocrática sobre a opinião pública. Esse artifício se baseia na ideia implícita de que toda técnica destinada a solucionar o desafio alimentar no mundo é moralmente justificável e, portanto, deve ser aplicada. Valendo-se de argumentações mecanicistas nunca demonstradas, o imperativo tecnocrático apresenta como objetivamente necessário àquilo que é econômica e ideologicamente oportuno. Ao legitimar o sistema dominante por meio de mistificações e teorias de veracidade não comprovada, a tecnocracia exerce um poder análogo ao desempenhado pela Igreja na Idade Média, nesse caso consagrando os efeitos negativos dos agrotóxicos como uma necessidade social inevitável (ABRASCO, 2015, p. 30).

Sendo assim, a degradação do meio ambiente rural e a expropriação capitalista no campo desde meados do século XX tem sido intensas, principalmente a partir da Revolução Verde, o que gerou desmatamentos, queimadas, erosão do solo, contaminação dos recursos hídricos, agricultores com problemas de saúde, dentre outros.

\section{CONSIDERAÇÕES FINAIS}

Após essa breve revisão bibliográfica, estando dividida em seções, objetivou-se resgatar histórica e criticamente os processos de transformação do espaço rural brasileiro no PósGuerra, destacando-se as décadas de 1970 e 1990. Cada seção teve por objetivo levantar algumas discussões que marcaram essas transformações, sendo a primeira seção referente às formas de intervenção e estratégias de desenvolvimento rural adotada pelo Estado à inserção do Modo de Produção Capitalista no espaço rural. A segunda seção apontou para as consequências dessa inserção, como a reestruturação agropecuária, movimentos de resistência bem como impactos principalmente socioambientais.

Entre algumas considerações, destacamse, os novos rumos do rural, marcado pelo 


\section{NEUMANN,E., FAJARDO,S. e MARIN,M.Z. \\ AS TRANSFORMAÇÕES RECENTES NO ESPAÇO RURAL BRASILEIRO: ANÁLISES DO PAPEL DO ESTADO NAS POLÍTICAS DE DESENVOLVIMENTO RURAL DAS DÉCADAS DE 1970 A 1990}

crescimento das atividades não agrícolas, que passam a representar estratégias de reprodução socioeconômica de agricultores familiares. Esse aumento das atividades não agrícolas leva ao espaço rural uma nova dinâmica e diversificação de estratégias para obtenção de renda.

Esse crescimento de atividades não agrícolas é decorrente do desenvolvimento tecnológico representado pela melhoria e expansão das vias de comunicação, como estradas, telefonia e meios de transporte. Surgem, portanto, novas relações campo-cidade, alterando a vida e o trabalho, influenciando, inclusive, a atuação dos movimentos sociais do campo que lutam pelo acesso a terra no país (MARAFON, 2011, p. 71).

Intensificam-se as relações entre atividades agrícolas e não agrícolas no espaço rural ou urbano como estratégia de geração de renda.

Nesse contexto, as "novas" atividades que surgem no espaço rural estão ligadas a indústria, comércio, prestação de serviços, lazer, entre outras. Elas trazem ao rural novas funções as quais ele não tinha anteriormente (ou tinha, mas de modo, sobretudo, tradicional).

Conforme Marafon (2011), o rural emerge como um espaço híbrido, que apresenta um complexo jogo de inter-relações com agentes naturais e sociais e uma grande diversidade e dinamismo.

\section{REFERÊNCIAS BIBLIOGRÁFICAS}

ALENCAR, M. T; MENEZES, A. V. C. Ação do Estado na produção do espaço rural: transformações territoriais. Campo-Território: revista de Geografia agrária, v.4, n.8, p.121-147, ago. 2009.

ALMEIDA, J.; NAVARRO, Z. (orgs.). Reconstruindo a agricultura: ideias e ideais na perspectiva do desenvolvimento sustentável. Porto Alegre: editora da UFRGS, 1997.

BARRETO, C. A; RIBEIRO, H. Agricultura e meio ambiente em Rio Verde (GO). Gestão Integrada em Saúde do Trabalho e Meio Ambiente [online], vol. 3, n. 1, artigo 5, jan.-abr. 2008.
BRASIL. LEI № 11.326 de 24 de Julho de 2006, Art. 3ㅇ․

Estabelece as diretrizes para a formulação da Política Nacional da Agricultura Familiar e Empreendimentos Familiares Rurais. Disponível em:

https://www.planalto.gov.br/ccivil_03/_Ato20042006/2006/Lei/L11326.htm>. Acesso em: 27 de jul. 2015.

BRASIL - IBGE - Instituto Brasileiro de Geografia e Estatística. Censo Agropecuário (2006). Pesquisa Agrícola Municipal (PAM - 2009). Disponível em: <http://www.ibge.gov.br>. Acesso em: mar/2015.

BRAUN, M. B. S. Uma análise da balança comercial agrícola brasileira a guisa de sua evolução histórica recente. Informe GEPEC, Toledo, v. 8, n. 1, p. 1-21, jan./jun. 2004.

BRUM, A. J. Modernização da agricultura no Planalto Gaúcho. ljuí: Fidene, 1983.

CANDIOTTO, L. Z. P; CORRÊA, W. K. Ruralidades, urbanidades e a tecnicização do Rural no contexto do debate cidade-campo. CAMPOTERRITÓRIO: revista de Geografia agrária, v.3, n. 5, p. 214-242, fev. 2008.

.Desenvolvimento rural sustentável: algumas considerações sobre o discurso oficial do Governo federal. Geografia, Rio Claro, v. 29, n. 2, 2004.

CARNeIRO, M. J. Política Pública e Agricultura: uma leitura do Pronaf: Estudos Sociedade e Agricultura. p. 70-82, abr. 1997.

Camponeses, agricultores e pluriatividade. Rio de Janeiro: Contra Capa, 1998. ᄀר_. Pluriatividade no campo: o caso francês. RBCS, n. 32, ano 11, out. 89-101, 1996.

Ruralidade: novas identidades em construção. Estudos Sociedade e Agricultura. n. 11, p.53-75, out. 1998.

CARNEIRO, F. F.; AGUSTO, L. G. S.; RIGOTTO, R. M.; FRIEDRICH, K.; BÚRIGO, A. C (Orgs). Dossiê ABRASCO: um alerta sobre os impactos dos agrotóxicos na saúde. Rio de Janeiro: EPSJV; São Paulo: Expressão Popular, 2015. Disponível em: < http://aspta.org.br/wpcontent/uploads/2015/05/DossieAbrasco_2015_ web.pdf>. Acesso em: jan. 2016. 


\section{NEUMANN,E., FAJARDO,S. e MARIN,M.Z. \\ AS TRANSFORMAÇÕES RECENTES NO ESPAÇO RURAL BRASILEIRO: ANÁLISES DO PAPEL DO ESTADO NAS POLÍTICAS DE DESENVOLVIMENTO RURAL DAS DÉCADAS DE 1970 A 1990}

DEPONTI, C. M. Teoria social e o lugar da agricultura familiar na sociedade contemporânea: estudo analítico-comparativo das contribuições brasileiras ao debate. In: XLV Congresso da Sociedade Brasileira de Economia, Administração e Sociologia Rural. Londrina, 2007.

FAJARDO, S. Territorialidades corporativas no rural paranaense. Guarapuava: Unicentro, 2008.

FERNANDES, B. M. A Formação do MST no Brasil. Petrópolis. Rio de Janeiro: Editora Vozes, 2000.

O MST e as Reformas Agrárias do Brasil. Boletim Dataluta. dez. 2008.

GAZOLLA, M. e SCHNEIDER, S. Qual "Fortalecimento" da Agricultura Familiar? Uma análise do Pronaf crédito de custeio e investimento no Rio Grande do Sul. RESR, Piracicaba-SP, Vol. 51, № 1, p. 045-068, Jan/Mar 2013 - Impressa em Abril de 2013.

GONÇALVES, Reinaldo. Globalização e desnacionalização. São Paulo: Paz e Terra, 1999.

GRAZIANO DA SILVA, José Graziano da. A nova dinâmica da agricultura brasileira. Campinas: UNICAMP. IE, 1996a. 217p.

O novo Rural Brasileiro. Revista Nova Economia. Belo Horizonte. 7(1): 43-81 (maio de 1997).

Os desafios das agriculturas brasileiras. A agricultura brasileira: desempenho, desafios e perspectivas. Brasília: IPEA, p. 157-183, 2010.

Progresso Técnico e Relações de Trabalho na agricultura. São Paulo - SP: Hubitec, 1981.

HESPANHOL, RAM. Agroecologia: limites e perspectivas. In: ALVES, AF; CARRIJO, BR; CANDIOTTO, LZP (orgs.). Desenvolvimento territorial e agroecologia. São Paulo: Expressão Popular, 2008b.

JORDÃO, A. P. F.; STAMPA, I. T. Precarização e informalidade no "mundo do trabalho" no Brasil: notas para reflexão. Universidade Federal do Maranhão - UFMA. São Luiz, 2015.

LAMARCHE, H. (Coord.). A agricultura familiar: uma realidade multiforme. Campinas: Editora da Unicamp, 1993.

LAMARCHE, Hugues (Coord.). Trad. Fréderic Bazin.A Agricultura Familiar: comparação internacional, v.2, Campinas, São Paulo: editora da UNICAMP, 1998.
MAIA, K. F. Tensões e contradições do agronegócio no Brasil: uma revisão bibliográfica. Encontro das redes de estudo rurais: Desenvolvimento, ruralidades e ambientalização - paradigmas e atores em conflito. 2012.

MARAFON, G. J. Principais transformações em curso no Espaço rural na atualidade. Revista Geográfica de America Central. Número especial. p. 69-84. 2011.

MARIN, M. Z. Políticas de Desenvolvimento Rural e Estratégias de reprodução na Agricultura Familiar da Quarta Colônia - RS. (Tese de Doutorado). UFSC. 2010.

MARQUES, M. I. M. O conceito de espaço rural em questão. Terra Livre. São Paulo, v. 2, n. 19, jul/dez. p. 95-112, 2002.

MATOS, P. F.; PESSÔA, V. L. S. Observação e entrevista: construção de dados para a pesquisa qualitativa em geografia agrária. In: RAMIRES, J. C. de L. ; PESSÔA, V. L. S (Org.). Geografia e pesquisa qualitativa: nas trilhas da investigação. Uberlândia: Assis Editora, 2009. p. 279-291.

MATTEI, L, F. A reforma agrária brasileira: evolução do número de famílias assentadas no período pós-redemocratização do país. Estudo Sociedade e Agricultura, Rio de Janeiro, vol. 20, n. 1, 2012: 301-325

Políticas públicas de fomento à produção familiar no Brasil: o caso recente do Pronaf. Congresso da Sociedade Brasileira de Economia e Sociologia Rural (Sober). Fortaleza (CE), julho de 2006.

Dez anos de Pronaf: síntese da produção e do debate acadêmico sobre o programa. Brasília: MDA, $2006 a$.

MELO, N. de A. Do complexo rural à modernização agrícola brasileira: a modernização da agricultura paranaense e os impactos na vida rural - uma análise do programa vilas rurais no norte do Paraná. Revista GeoAtos. Departamento de Geografia da FCT/UNESP, Presidente Prudente, n. 11, v.1, janeiro a junho de 2011, p. 58-76.

MELO, F. H. de O crescimento agrícola brasileiro dos anos 80 e as perspectivas para os anos 90 . Revista de Economia Política, São Paulo, 10(3): p. 22-30, jul./set. 1993. 


\section{NEUMANN,E., FAJARDO,S. E MARIN,M.Z. \\ AS TRANSFORMAÇÕES RECENTES NO ESPAÇO RURAL BRASILEIRO: ANÁLISES DO PAPEL DO ESTADO NAS POLÍTICAS DE DESENVOLVIMENTO RURAL DAS DÉCADAS DE 1970 A 1990}

NAVARRO, Z. Desenvolvimento Rural no Brasil: os limites do passado e os caminhos do futuro. In: Estudos Avanços, v. 15 (43), 2001.

OLIVEIRA, G. B. Uma discussão sobre o conceito de desenvolvimento. Revista da FAE, v.5, no 2, Curitiba, 2002.

PESSÔA, V. L. S. Geografia e Pesquisa Qualitativa: um olhar sobre o processo investigativo. In: Geo UERJ- Rio de Janeiro, ano 14, no. 23, v.1, 1은 semestre de 2012, p. 4-18. Disponível em: < http://www.e-

publicacoes.uerj.br/index.php/geouerj/article/vie w/3682/2554>. Acesso em: jul de 2015.

REZENDE, G. C. Agricultura e ajuste externo no Brasil: novas considerações. Revista de Economia Política, v. 12, dez de 1989. p. 56-72.

RICCI, Ruddá. Terra de Ninguém: Representação sindical rural no Brasil. Campinas: Unicamp, 1999.

RÜCKERT, Aldomar A. Metamorfoses do território: a agricultura de trigo/soja no Planalto Médio Rio-grandense (1930-1990). Porto Alegre: editora da UFRGS, 2003.

- Reforma do Estado, reestruturações territoriais, desenvolvimento e novas territorialidades. GEOUSP - Espaço e Tempo, São Paulo, no 17, p. 79 - 94, 2005.

SAUER, S. Agricultura familiar versus agronegócio: a dinâmica sociopolítica do campo brasileiro. Embrapa Informação Tecnológica. Brasília-DF, 2008.

SCHNEIDER, S. A Pluriatividade na Agricultura Familiar. 2. ed. Porto Alegre: Editora da UFRGS, 2009a.
Agricultura familiar e industrialização: Pluriatividade e descentralização industrial no Rio Grande do Sul. Porto Alegre: UFRGS, 1999.

A pluriatividade como estratégia de reprodução social da agricultura familiar no Sul do Brasil. Estudos Sociedade e Agricultura, Rio de Janeiro, v. 16, p. 164-184, 2001.

. A pluriatividade na agricultura familiar. Porto Alegre (RS): Editora da UFRGS, 2003.

SCHNEIDER, S; CAZELLA, Ademir Antônio; MATTEI, Lauro. Histórico, caracterização e dinâmica recente do Pronaf. In: SCHNEIDER, Sérgio; SILVA, Marcelo Kunrath; MARQUES, Paulo E.M. (orgs.). Políticas públicas e participação social no Brasil rural. Porto Alegre: editora da UFRGS, 2004.

SILVA, I. M. de. A Contag em perspectiva: um estudo sobre a formação política. 2013. $157 \mathrm{f}$. Dissertação (mestrado) - Universidade Federal Rural do Rio de Janeiro - Instituto de Ciências Humanas e Sociais.

SILVA, R. A. da.; MACIEL, L. S. C. da.; MOREIRA, M. F. de. Zoneamento Ambiental - Um Estudo De Caso Do Processo De Uso E Ocupação Do Solo No Município De Uberlândia. Revista GEOGRAFIA EM ATOS. Departamento de Geografia da FCT/UNESP, Presidente Prudente, n. 13, v.1, janeiro a junho de 2013, p. 66-87.

SILVA, M. F. da; ALMEIDA, J. A.. Turismo rural: família, patrimônio e trabalho. In: RIEDL, Mario; ALMEIDA, Joaquim Anécio; VIANA, Andyara Lima Barbosa (orgs.). Turismo rural: tendências e sustentabilidade. Santa Cruz do Sul: EDUNISC, 2002 